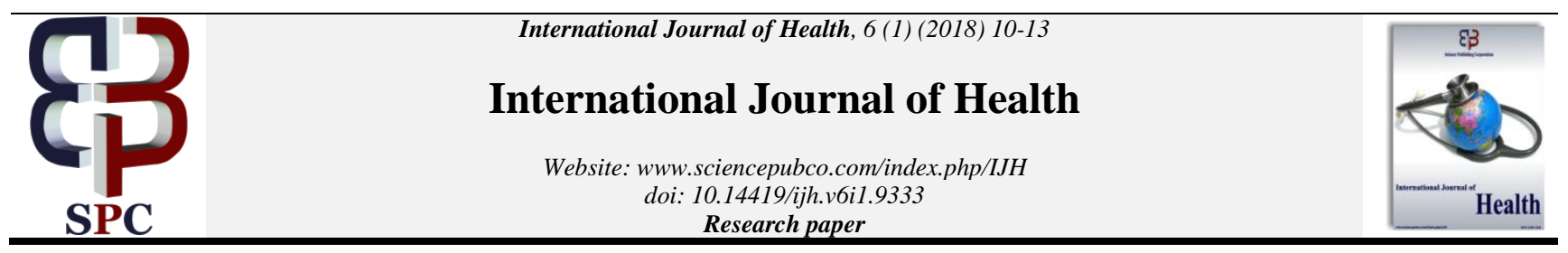

\title{
Comparing health risk behaviors of Franklin County youth with their national and statewide counterparts: An ecological study in the state of Kentucky
}

\author{
Herman Walston ${ }^{1}$, Angela F. Meshack ${ }^{2 *}$, Timothy Latham ${ }^{3}$, Warith Majid ${ }^{4}$, Ronald J. Peters Iii ${ }^{4}$, \\ Timothy Gans ${ }^{4}$, Anthony P. Peters G ${ }^{4}$ \\ ${ }^{1}$ Professor, School of Education, Kentucky State University \\ ${ }^{2}$ Associate Professor, College of Education, Texas Southern University \\ ${ }^{3}$ Research Associate, School of Education, Kentucky State University \\ ${ }^{4}$ Research Intern, School of Education, Kentucky State University \\ *Corresponding author E-mail: meshackaf@tsu.edu
}

\begin{abstract}
While national surveillance studies have stratified high school students' health behavior outcomes, few ecological data sets have been explored, collected, and analyzed on the unique health problems of minority children. An area for which limited data on minority youth has been collected is Franklin County, home of the state capital of Kentucky. In the current study, we use baseline data collected in 2015 from students attending two high schools that were sites for Kentucky State University's Youth Empowerment Project. We hypothesize that youth who reside in Franklin County would report lower maladjusted behaviors than their national and statewide counterparts in the same year of observation. Data analyses confirm that compared to their national- and state-level counterparts, Franklin County high school students were less likely to report riding with a driver who had been drinking alcohol, engaging in sexual intercourse, drinking alcohol before sexual intercourse, and experiencing non-condom use when engaged in sexual intercourse, forced sexual intercourse, dating violence, cyber bullying, suicidal ideation, and drug use. These findings suggest that Franklin County high school students may be exposed to environmental variables that may be preventive to maladjusted behaviors.
\end{abstract}

\section{Introduction}

Prior research includes alarming data about the academic, social, and health disparities facing minority youth with much of the current research describing this group as a disparate population (DiClemente, 2001; Peters et al., 2010; Williams \& Mohammed, 2010). According to United States Public Law 106-525 (2000), disparate populations are those with significant differences in overall prevalence, incidence, mortality, or survival rates related to diseases or conditions that affect health outcomes in comparison to the general population. The disparate population is disproportionately predisposed to negative health outcomes due to economic reasons (Dawkins, Shen, \& Sanchez, 2005; Kalousova \& Danziger, 2013; McLoyd, Jayaratne, Ceballo, \& Borquez, 1994; Williams, 2012), environmental reasons (Costello, Keeler, \& Angold, 2001; Dawkins et al., 2005; Williams, 2012), and/or societal reasons (Allen, 2007; Kleven, 2009; Ornelas et al., 2009).

Franklin County, Kentucky, has a population of approximately 50,000 residents and serves as the seat of the state capital. Recent data reported that nearly one-quarter of children in Franklin County reside in poverty. In addition, $43 \%$ of children in Franklin County live in single-parent households, compared to $34 \%$ statewide (RWJ Foundation, 2016). The link between poverty or low socioeconomic status and poor physical and mental health is well documented (Centers for Disease Control and Prevention [CDC], 2018).

Over the past 2 decades, researchers have increasingly recognized the importance of environmental influences on youth development (Ross,
2000). Specifically, living in a disadvantaged community, typically defined as one with a high concentration of minority families below the poverty level, is associated with a wide range of negative outcomes in early childhood and youth development. Adolescents who live in poverty are at an elevated risk for conduct problems, substance use, poverty-related stress, and depression (Ross, 2000; Ross \& Mirowsky, 2001; Steptow \& Feldman, 2001).

While national surveillance studies have collected and stratified health behavior outcome data for Kentucky high school students through the Kentucky Youth Risk Behavior Survey (Kahn, 2016), limited ecological data have been collected and analyzed among the unique population of minority children living in Franklin County (US Census Bureau, 2016). They are unique in that as minorities they make up a small percentage of the general population and they are among the poorest residents in the area. The current study uses baseline data collected in 2015 from students attending two high schools that participated in Kentucky State University's Youth Empowerment Project (KSU-YEP; Walston, Meshack, \& Peters, 2017). We hypothesize that youth who reside in Frankfort County with access more access to interventions would observe fewer maladjusted behaviors than their national and statewide counterparts in the same year of observation.

\section{Methods}

KSU-YEP is a holistic program implemented in 2015 to serve among African American and Hispanic youth between the ages of 10 and 17 attending school in Franklin County. Prior to beginning 
the study, it was approved by the Institutional Review Board of Kentucky State University. The investigative team met with administrators representing two large school districts in the Frankfort, Kentucky area seeking permission to conduct the study among students on their campuses. After verbal agreement was obtained from the schools' administrators, a memorandum of understanding was signed, granting the study team access to their students, faculty, and staff to assist with data collection and survey administration. A contact person/coordinator at each school was assigned by the respective administrators to serve as the liaison between the school and the investigative team.

Students were given a consent form to take home to their parents or guardians. Those students who returned their signed consent forms were considered eligible for study participation. Inclusion criteria for KSU-YEP participants included enrollment in a school in either district, the ability to speak, read, and write English, and parental permission. Informed consent was required of all participants. Individuals not returning consent forms or whose parents indicated they did not wish them to participate were deemed ineligible to take part in the study.

With university and school district approval, the study began with the collection of baseline data. Trained research assistants collected baseline surveys by meeting with students in the schools' common areas that were not in use at the time data collection commenced. The importance of the study and the procedures in place to assure confidentiality were explained to students before each data collection period began. Students who did not wish to participate were escorted back to their classrooms by a member of the study team. To obtain the maximum number of student responses, reasonable efforts (at least two attempts within a 2-week period of the original study date) were made to locate and survey students who were absent during scheduled survey administration days. The data collection team consisted of a field director and two data collectors, both assigned to gather participant data. All received training from the project's director and were knowledgeable of the study's objectives and the rights of human subjects.

\section{Measures}

An abbreviated version of the National Youth Risk Behavior Survey (YRBS) was used in this cross-sectional study. The YRBS was developed in 1990 to monitor priority health risk behaviors that contribute markedly to the leading causes of death, disability, and social problems among youth and adults in the United States (Brener et al., 2004). These behaviors, often established during childhood and early adolescence, include behaviors that contribute to unintentional injuries and violence, sexual behaviors related to unintended pregnancy and sexually transmitted infections, including HIV, and alcohol use. The CDC has conducted two test-retest reliability studies of the national YRBS questionnaire, one in 1992 and the other in 2000. In the first study, the questionnaire was administered on two occasions, 14 days apart, to a convenience sample of 1,679 students in grades 7 through 12 (Brener et al., 2004) Approximately three-fourths of the items were rated as having a substantial or higher reliability (kappa $=61 \%-100 \%$ ), and no statistically significant differences were observed between the prevalence estimates for the first and second times that the questionnaire was administered. The responses of seventh grade students were less consistent than those of students in higher grades, indicating that the questionnaire is best suited for students in eighth grade or higher.

\section{Results}

\subsection{Demographic data}

The 95 students of KSU-YEP were primarily African American (85.7\%). Hispanic Americans (12.9\%) were also represented. The majority $(86.2 \%)$ of respondents were currently in 9 th $(26.6 \%)$, 10th $(37.2 \%)$, and 11 th $(22.3 \%)$ grades. Most of the sample reported that they were age $15(34.0 \%)$, age $16(25.5 \%)$, or age $17(23.4 \%)$. In addition, $57.5 \%$ of participants were female.

Vehicle Related Behaviors Related to Unintentional Injuries In the 30 days before the survey, $20 \%$ of students nationwide had reported riding in a car or other vehicle one or more times with a driver who had been drinking alcohol. Franklin County teens were more than three times less likely to take part in this maladjusted behavior compared to their overall counterparts in the state of Kentucky $(19.5 \%$ versus $5.9 \%)$. Nationally, $41.5 \%$ had texted or emailed while driving a car or other vehicle on at least 1 day during the 30 days before the survey. This percentage was higher statewide than among Franklin County students $(53.4 \%$ versus $36.5 \%)$. Nationally, $6.1 \%$ of students reported that they rarely or never wore a seat belt when riding in a car driven by someone else. In Kentucky, this percentage was higher at both the state and county level $(21.8 \%$ and $9.1 \%$ )

\subsection{Weapon-related behaviors related to intentional and unintentional injuries}

Nationwide, $16.2 \%$ of students had carried a weapon (e.g., gun, knife, or club) on at least 1 day during the 30 days before the survey. High school students in Franklin County were more likely to report weapon carrying than their counterparts throughout the state of Kentucky ( $25.3 \%$ versus $23.1 \%$ ). Nationwide, $4.1 \%$ of students had carried a weapon on school property on at least 1 day during the 30 days before the survey. This percentage was lower in Franklin County students $(2.3 \%)$ than among their state level counterparts (7.2\%).

\subsection{Sexual behaviors related to unintended pregnancy and sexually transmitted infections, including HIV infec- tion}

Nationwide, $41.2 \%$ of students reported having had sexual intercourse during their lifetimes. Students throughout the state of Kentucky reported similar prevalence rates $(41.7 \%)$; however, Franklin County students were less likely (36.2\%) to report lifetime sexual intercourse. Nationwide, $20.6 \%$ of students reported drinking alcohol or using drugs before their last sexual intercourse. Comparatively, students throughout the state of Kentucky (17.1\%) and in Franklin County (10.3\%) reported less alcohol drinking during sexual intercourse. Nationwide, $56.9 \%$ of students reported that either they or their partners had used a condom during their last sexual intercourse. While a higher prevalence was observed among students throughout the state of Kentucky (53.9\%), Franklin County students reported less noncondom use (44.8\%).

\subsection{Violence related to sexual behaviors}

Nationwide, $10.6 \%$ of students had been forced to participate in sexual acts (e.g., being kissed, touched, or physically forced to have sexual intercourse) by someone they were dating or going out with one or more times during the 12 months before the survey. Although students throughout the state of Kentucky reported similar prevalence rates $(10.1 \%)$, Franklin County students were less likely to report sexual assault (5.4\%). In addition, nationally, $9.6 \%$ of students who dated or went out with someone during the 12 months before the survey reported being intentionally hurt physically (e.g., hit, slammed into something, or injured with an object or weapon) by the person they were dating. Although students throughout the state of Kentucky reported similar prevalence rates (8.9\%), Franklin County students reported less physical assault $(6.9 \%)$ by a partner.

\subsection{School-related violence and cyberbullying}

Nationwide, $20.2 \%$ of students reported that they had been bullied on school property during the 12 months before the survey. Although students throughout the state of Kentucky reported a slightly higher prevalence $(22.0 \%)$ of bullying, fewer Franklin County 
students reported experiencing these violent events (10.3\%). Throughout the nation, $15.5 \%$ of students had been electronically bullied through email, chat rooms, instant messaging, websites, or texting during the 12 months before the survey. Again, Kentucky students observed a slightly higher prevalence (17.0\%), while their Franklin County counterparts reported less than half (6.9\%) of these violent events.

\subsection{Suicidal ideation and behaviors}

Nationwide, $17.7 \%$ of students had seriously considered attempting suicide during the 12 months before the survey. Although students throughout the state of Kentucky reported similar prevalence rates $(15.7 \%)$, Franklin County students reported lower rates (6.9\%). Nationally, $14.6 \%$ of students had made a plan about how they would attempt suicide. Students throughout the state of Kentucky reported similar prevalence rates (13.9\%), while Franklin County students reported fewer $(5.2 \%)$ serious contemplations of suicide.

\subsection{Drug use behaviors}

Cigarettes Nationwide, $32.3 \%$ of students had tried cigarette smoking (even one or two puffs) in their lifetimes. Students in the state of Kentucky overall showed a higher lifetime prevalence of cigarette smoking (44.1\%), while Franklin Country students reported much less $(29.3 \%)$. Nationwide, $10.8 \%$ of students had smoked cigarettes on at least 1 day during the 30 days before the survey (i.e. current cigarette use). Students in the state of Kentucky were more likely to report current cigarette use (16.9\%), while Franklin County students were less likely to report current cigarette use $(10.5 \%)$

Alcohol Nationwide, $63.2 \%$ of students had at least one drink of alcohol during their lifetimes. Conversely, students in Kentucky statewide (56.8\%) and in Franklin County (34.5\%) reported a lower lifetime prevalence of alcohol use. In addition, nationally, $32.8 \%$ of students had had at least one drink of alcohol on at least 1 day during the 30 days before the survey (i.e., current alcohol use). This percentage was also lower among state- $(28.5 \%)$ and county-level students $(17.2 \%)$

Marijuana Nationwide, $38.6 \%$ of students had used marijuana one or more times during their lifetimes. Comparatively, statewide $(33.1 \%)$ and county level $(36.8 \%)$ reporting was slightly lower. $\mathrm{Na}-$ tionwide, $21.7 \%$ of students had used marijuana one or more times during the 30 days before the survey (i.e., current marijuana use). Comparatively, students statewide (17.2\%) and in Franklin County $(24.6 \%)$ reported slightly lower results.

\section{Discussion}

Compared to their national- and state-level counterparts, Franklin County high school students were less likely to report riding with a driver who had been drinking alcohol, engaging in sexual intercourse, drinking alcohol before sexual intercourse, and experiencing noncondom usage, forced sexual intercourse, dating violence, cyber bullying, suicidal ideation, and drug use. These findings suggest that Franklin County high school students may be exposed to protective environmental factors that help to prevent such behaviors.

Overwhelming evidence seems to support the conclusion that high school students in rural areas are more vulnerable to participation in at-risk behaviors than their urban counterparts (Fromme, Corbin, \& Kruse, 2008; Robinson, Price, Thompson, \& Schmalzried, 1998). In multiple instances, this was not the case for students in Franklin County. The identification of the protective factors present among teens in Franklin County may provide a better understanding of what may work nationwide to assist young people at risk for unsafe behaviors. The authors hypothesize that youth living in Franklin County may have exposure to significant social, cultural, and community resources.
This is one of the first health behavior studies designed to explore the differences between a cross-section of high school students in Franklin County, the state of Kentucky, and the United States. Because this ecology study is not reflective of significant testing, the findings from this study must be interpreted with caution. There are four limitations to the current study. Because of the small sample of students in the current study, conclusions regarding Franklin County high school students are extremely limited. Although this study provides a start, larger comparative studies will provide a more accurate reflection of the rates of the explored health behaviors. Second, data for this study were taken from participants entering a health education program in Franklin County. The sample size and the limited area from which student respondents were drawn limit the generalizability of the study's results. Third, this study does not reflect the entire youth population in Franklin due to the lack of inclusion of White youth. Last, the present study is limited by the number and types of questions asked of the participating students. Nonetheless, the data uncovered in this research offer potential direction for larger studies investigating the causal differences in participation in high risk behaviors among high school students in Franklin County, the state of Kentucky, and the United States.

\section{References}

[1] Allen, T. D. (2007). Katrina: Race, class, and poverty: Reflection and analysis. Journal of Black Studies, 37(4), 466-468. https://doi.org/10.1177/0021934706296184.

[2] Brener, N. D., et al. (2004). Methodology of the youth risk behavior surveillance system. MMWR. Recommendations and reports: Morbidity and mortality weekly report. Recommendations and reports/Centers for Disease Control, 53(RR-12), 1-13.

[3] Centers for Disease Control and Prevention. (2015). High School YRBS Participation History \& Data Quality, 1991-2015. Retrieved from: https://www.cdc.gov/healthyyouth/data/yrbs/participation.htm.

[4] Costello, E. J., Keeler, G. P., \& Angold, A. (2001). Poverty, race/ethnicity, and psychiatric disorder: A study of rural children. American Journal of Public Health, 91(9), 1494-1498. https://doi.org/10.2105/AJPH.91.9.1494.

[5] Dawkins, C. J., Shen, Q., \& Sanchez, T. W. (2005). Race, space, and unemployment duration. Journal of Urban Economics, 58(1), 91113. https://doi.org/10.1016/j.jue.2005.02.001.

[6] Fromme, K., Corbin, W. R., \& Kruse, M. I. (2008). Behavioral risks during the transition from high school to college. Developmental psychology, 44(5), 1497. https://doi.org/10.1037/a0012614.

[7] Kahn, L. (2016). Youth risk behavior surveillance-United States, 2015. MMWR. Surveillance Summaries, 65. (6) 1-174. https://doi.org/10.15585/mmwr.ss6506al.

[8] Kalousova, L. \& Danziger, S. (2013). Racial disparities in economic well-being in the Detroit metropolitan area after the great recession. National Poverty Center Working Paper Series.

[9] McLoyd, V. C., Jayaratne, T. E., Ceballo, R., \& Borquez, J. (1994). Unemployment and work interruption among African American single mothers: Effects on parenting and adolescent socioemotional functioning. Child Development, 65(2), 562-589. https://doi.org/10.2307/1131402.

[10] Ornelas, I. J., Amell, J., Tran, A. N., Royster, M., Armstrong-Brown, J., \& Eng, E. (2009). Understanding African American men's perceptions of racism, male gender socialization, and social capital through PhotoVoice. Qualitative Health Research, 19(4), 552 -565. https://doi.org/10.1177/1049732309332104.

[11] Peters, R. J., Meshack, A., Amos, C., Scott-Gurnell, K., Savage, C., $\&$ Ford, K. (2010). The association of drug use and post-traumatic stress reactions due to Hurricane Ike among Fifth Ward Houstonian youth. Journal of Ethnicity in Substance Abuse, 9(2), 143-151. https://doi.org/10.1080/15332641003772702.

[12] Robert Wood Johnson Foundation. (2015). County Health Rankings. Retrieved from:

[13] http://www.countyhealthrankings.org/app/kentucky/2015/rankings/franklin/county/factors/4/snapshot.

[14] Robinson, K. L., Price, J. H., Thompson, C. L., \& Schmalzried, H. D. (1998). Rural junior high school students' risk factors for and perceptions of teen-age parenthood. Journal of School Health, 68(8), 334-338. https://doi.org/10.1111/j.1746-1561.1998.tb00596.x. 
[15] Ross, C. (2000). Neighborhood disadvantage and adult depression. Journal of Health and Social Behavior, 41, 177-187. https://doi.org/10.2307/2676304.

[16] Ross, C., \& Mirowsky, J. (2001). Neighborhood disadvantage, disorder, and health. Journal of Health and Social Behavior, 42, 258276. https://doi.org/10.2307/3090214.

[17] Steptoe, A., \& Feldman, P. J. (2001). Neighborhood problems as sources of chronic stress: Development of a measure of neighborhood problems, and associations with socioeconomic status and health. Annals of Behavioral Medicine, 23(3), 177-185. https://doi.org/10.1207/S15324796ABM2303 5.

[18] United States Census Bureau. Quick Facts: Franklin County, Kentucky. (2016). retrieved from: http://www.census.gov/quickfacts/table/PST045215/21073.

[19] Walston, H., Meshack, A., \& Peters, R. J. (2017). Intervention methodologies targeting vulnerable youth in Frankfort, Kentucky: Measuring developmental assets. International Journal of Social Science Studies, 5(9). https://doi.org/10.11114/ijsss.v5i8.2429.

[20] Williams, D. \& Mohammed, S. (2010). Discrimination and racial disparities in health: Evidence and needed research. Journal of Be havioral Medicine, 32(1), 20. https://doi.org/10.1007/s10865-0089185-0.

[21] Williams, D. (2012). Race, ethnicity and crime: Alternate perspectives. New York, NY: Algora Publishing. 